\title{
Bridging the divide: embedding voice-leading analysis in string pedagogy and performance
}

\author{
Deborah Mawer
}

\begin{abstract}
Experience as a music lecturer in higher/further education and as an instrumental teacher suggests that instrumental pedagogy - focused on strings - and music analysis could usefully be brought closer together to enhance performance. The benefits of linkage include stimulating intellectual enquiry and creative interpretation, as well as honing improvisatory skills; voiceleading analysis, particularly, may even aid technical issues of pitching, fingering, shifting and bowing. This article details an experimental curriculum, entitled 'Voice-leading for Strings', which combines voice-leading principles with approaches to string teaching developed from Nelson, Rolland and Suzuki, supplemented by Kodály's hand-signs. Findings from informal trials at Lancaster University (1995-7), which also adapted material for other melody instruments and keyboard, strongly support this perceived symbiotic relationship.
\end{abstract}

\section{Introduction}

Despite recent developments, a somewhat artificial separation persists at higher levels of musical training in the UK, and elsewhere, between academic (including analytical) and performing disciplines. Consequently, musicians themselves find it difficult to avoid a similar polarisation in their own attitudes and subsequent teaching. Various publications (from the pioneering Cone, 1968; Forte \& Gilbert, 1982; Cook, 1987; Dunsby \& Whittall, 1988; Aldwell \& Schachter, 1989) have altered the perception of analysis. However, early attempts at partnering analysis and performance - and by extension their teaching - have tended to suffer from over-prescriptive approaches as, for instance, in Berry's otherwise admirable book (1989). Implicit in Berry's work was a sense that the partnership was unequal and that analysis, rather than performance, was privy to most of the answers.

Conversely, other texts have rather downplayed the need for analytical rigour (including, despite its title, Bruhn, 1993). That the idea of relating analysis and performance is seen as increasingly important in the 1990s is, however, witnessed by the emergence of combined courses in higher education, including the joint course between King's College London and the Royal Academy of Music. Such increased seriousness in the pursuit of musical synthesis is also symbolised by an important book on The Practice of Performance (Rink, 1995) which argues for an equal partnership between performance and analysis, demonstrating that performance may inform analysis as much as the reverse.

With specific reference to string pedagogy, my own ideas have been strongly influenced by Sheila Nelson, while working on the Tower Hamlets String Project (Nelson, 1985) and at the Pimlico Centre for Young Musicians. Nelson's project (with its teaching materials published by Boosey \& Hawkes) was distinctive in its 
holistic educational ethos which sought to keep physical skills, aural awareness, and reading ability in balance within whole-class teaching (both primary and some secondary), across a two-year programme. The scheme was to some extent a British counterpart to, and sequel of, Paul Rolland's project at the University of Illinois (Rolland, 1974). It also synthesised ideas of Shinichi Suzuki and Zoltán Kodály (see Choksy, 1988; Rainbow, 1990).

The incorporation of an analytical dimension within this type of integrated curriculum represents a natural extension, part of the impetus for which comes from my involvement with the Society for Music Analysis (SMA) and a belief that analysis should be intellectually fascinating and fun (Mawer, 1992: 8). Other personal attempts to make analysis more accessible have included a multi-media software package which combines an analytical appreciation of a piece of music with 'realtime' listening, via a commercial CD; this package was produced by the Teaching Learning Technology Project (TLTP) and piloted at Lancaster University (Mawer, 1997). In terms of a broader context, my present study exhibits some parallels with recent work on incorporating rediscovered methods into contemporary piano teaching, as a way of informing piano technique, especially fingering (Gellrich \& Parncutt, 1998). My dual aims to increase the accessibility of music analysis and to encourage 'creative thought' are shared by an earlier contributor to this journal, Tim Howell (1996: 125), and, although our views on voice-leading analysis differ somewhat, further reference will be made to Howell's article later.

My article is an updated version of a paper invited for a Commission on the Education of the Professional Musician under the auspices of the International Society for Music Education (ISME), at the University of Florida in 1994. Some five years on, the questioning of means and goals in our educating of musicians, which characterised the 1994 Conference, seems just as important. Revision and continual development of teaching method, as well as reconsideration of teacher-student relationships (Bruhn, 1990), will always be necessary for music education to thrive. Instrumental teaching - and the teaching of performance in the broadest sense - must never be merely about technique and physicalities, but rather about the holistic development of musicianship (Wright, 1998), powers of thought, analysis, evaluation, communication, and self-development, including that of the teacher. In this way, the 'Voice-leading for Strings' proposal supported various objectives of the 1994 ISME Conference, especially the 'away from the star syndrome' (objective a) and the redefining of the role and status of the teacher (objective c). Beyond its initial focus on a central tonal repertory, the project also sought to 'transcend main-stream repertoire' (objective $d$ ) in its use of popular materials and exploration of a broader modality.

\section{Benefits of coupling analysis and performance}

Before exploring the specific, potential interplay between voice-leading analysis and string teaching and performance, it makes sense to outline the basic complementary relationship between the larger disciplines and the benefits which may accrue from their linkage. Although these benefits may be most keenly felt or most obviously lacking at advanced levels of learning, the majority seem essential for all-round musicianship and meaningful performance at any level.

Most generally, linking analysis and performance in professional training and teaching should stimulate the performer's intellectual faculties by fostering a spirit of enquiry and powers of investigation. (On the educational value of analysis, see also Howell, 1996: 125.) Conversely, this linkage should stimulate the analyst's imagina- 
tion and promote a broadmindedness that acknowledges performance to be much more than the mechanics of musical execution. This cross-disciplinary approach seeks to deepen a student's appreciation and enjoyment of a particular piece of music by encouraging interpretative strategies, triggered initially by deceptively simple questions such as: 'How does it work?' (see Eales' endorsement of 'challenge', 1992: 93). Beyond 'what?' and 'how?', one would hope to progress to 'why?' (a stance supported by Howell, 1996, 131).

We might reasonably expect that incorporating analysis into instrumental teaching should enable students to play with greater structural insight, at the same time informing their stylistic understanding - in tandem with an appreciation of historical performance practice. Beyond this, an integrated pedagogical approach could take on board the taxing matter of communicating structural understanding to an audience whether explicitly by suggestion - even contradiction - or, more likely, implicitly. Analytical (and historical) awareness in performance should increase discernment in selecting between interpretations, whether 'internal' or external - live or recorded. A final raison d'être for this coupling should be to assist in producing versatile musicians who can apply analytical and evaluative skills in future employment - as instrumental or classroom teachers, orchestral players, soloists, community musicians, arts administrators - or indeed for future recreation and pleasure.

\section{Benefits of voice-leading analysis in string teaching}

Analysis may be particularly beneficial for string players when broadly based on the voice-leading principles of Heinrich Schenker (1979) and his pupil Felix Salzer (1982), as put forward in Free Composition and Structural Hearing, respectively. Briefly, these principles involve hearing tonal music as organised into a hierarchy of levels, founded on the supremacy of consonance - ultimately of the tonic chord (and tonic note, as the fundamental pitch of the overtone series). The music is seen as projecting a large-scale two-part contrapuntal framework: its 'fundamental structure' (Ursatz). This framework consists of a cadential bass line and an upper melodic line ('fundamental line' [Urlinie]), which in Schenkerian music theory comprises scalic descents from the degrees me, soh and doh, of the common arpeggio. The directed motion from less stable to more stable pitches (e.g. $f a h-m e$; te-doh) gives rise to the term 'voiceleading'.

In this way, reductive voice-leading analysis helps to convince even the more sceptical student of the indisputable significance of scales (i.e. step-wise progressions, shape of 'fundamental line') and arpeggios (i.e. chordal diminution, basis of 'fundamental structure') in tonal music, and of the existence of similar frameworks for broader modal styles. An awareness of background structures and of successive layerings above, directed by an appreciation of which pitches are structural (essential) and which are decorative (inessential), has to assist in promoting a contrapuntal overview of a piece rather than the stultified note-by-note rendition. This power of analysis to make us step back and attempt to see a 'whole' is also acknowledged by Howell $(1996,125)$ in his more general discussion of the benefits of analysis.

Other benefits include facilitating technical problem-solving of pitching, fingering, position-shifts, ornamentation, phrasing, and indeed bowing (claims that will be substantiated below). From an understanding of voice-leading analysis in elucidating pitch (i.e. melody, counterpoint, register and harmony), we should be more receptive to the potential usefulness of analysing other parameters (e.g. time-span, metre, rhythm and timbre). Ultimately, strengthening the interface should encourage greater 
artistic creativity and confidence in performance of classical repertory, free improvisation, or extemporisation on a given framework; in voice-leading terms, exploring different 'composings out' of a 'fundamental structure'.

Despite these extensive potential benefits, some writers remain sceptical about encouraging voice-leading analysis, particularly at relatively early stages of learning (see Howell's stance regarding the undergraduate curriculum, Howell, 1996, 126-7). (Of course, if the basics were embedded even earlier, in a creative aurally-based fashion, as I am advocating, there would be more continuity between tertiary and non-tertiary education and therefore less problem with the present gap in understanding which is one of Howell's concerns.) Although we must guard against the mechanical or dogmatic employment of any technique, it would be a pity if undue caution over possible mishandling prevented us from promoting particular techniques when they seemed apt. Sensitively and intelligently employed in string teaching, voice-leading approaches can help to emphasise the varied sound-patterns of music over, for instance, the much more mechanical crutch of fixed finger-patterns. Although one can consider 'the nature of structural dissonance and resolution' and 'the unfolding of directed tonal motion through time' (Howell, 1996, 127) independently of any methodology, a broadly Schenkerian approach actively facilitates such enquiries. It offers a clear 'way in', especially for the relative novice. Otherwise, such issues may not get addressed at all.

\section{Curriculum content of 'Voice-leading for Strings'}

An important aspect of 'Voice-leading for Strings' involves the preparation of a learning package for students and teachers, initially for violin, which introduces structural analysis, presupposing experience of string performance (and pedagogy), but not necessarily any prior analytical training. This package aims to provide an applied understanding of voice-leading principles, based on the teachings of Schenker and Salzer. Such ideas are, however, employed flexibly and have been modified and updated for the needs of present-day string teaching (see especially Nelson, 1985; Rolland, 1974; Eales, 1992). Although these materials are intended primarily for small-group instrumental teaching, the main ideas could be adapted for work in performance and composition work in the school classroom. Materials are graded at beginner, intermediate, equivalent to the Associated Board of the Royal Schools of Music (ABRSM): Grade 5+ and advanced levels (ABRSM: Grade 8+). Broadly speaking, their intention is to develop analytical skills alongside technical ones, so that the three levels offer a parallel progression of string technique and analytical understanding. Having said this, an 'Introduction to Advanced Level' is aimed at the skilled student-player, schooled on more traditional string pedagogy, who lacks analytical experience.

The main advanced-level materials seek to demonstrate the strengths of more demanding, in-depth, voice-leading analyses, together with some 'formal' understanding, and are commensurate with a proficiency of string-playing typically achieved by the early stages of conservatoire or university education. Again, in addition to use in individual/small-group instrumental lessons, this material may be adapted to provide a more practical and engaging way of teaching structural analysis in the university lecture-room with much larger student groups. (Discussions with students on informal trials at Lancaster University suggest that this approach can significantly enliven the traditional academic curriculum: see below.)

Detailed case studies, with voice-leading and motivic analyses, accompanied by 
commentaries, serve as flexible models for the student's own interpretative approaches to the music. The aim is to stimulate thought and encourage reaction; crucially, there is no single right answer, though some approaches may work better than others. Case studies currently completed include those on J. S. Bach's Partita No. 1 in B minor and Béla Bartók's Sonata for Solo Violin ('Melodia'), as an extension of ideas in a twentieth-century post-tonal/modal setting. Beyond violin repertory, case studies include J. S. Bach's Cello Suite No. 1 in G major, both in original version and in transcription for viola (see Fig. 9).

\section{'Introduction to Advanced Level'}

The main focus of this article is on embedding basic analytical principles in the 'Introduction to Advanced Level' for violin, which, with certain modifications, also applies to viola and cello. It seems imperative that this material should work convincingly if the advanced case studies, reliant on this foundation, are to succeed. The 'Introduction' employs Kodály's system of hand-signs, with sol-fa nomenclature, and French time-names, in the belief that instrumental technique, analytical understanding, aural awareness (see Priest, 1989), and basic vocal training, go hand-inhand. Each element serves to strengthen the others (for further endorsement of integrated approaches, see Verney, 1991). The violinist is introduced to basic voiceleading melodic descents, from 31 (i.e. $m, r, d$; as in the opening phrase of Three Blind Mice), 5-1 ( $s, f, m, r, d$; basis of Twinkle, Twinkle Little Star) and, more unusually, 8-1 ( $d, t, l, s, f, m, r, d$; peel of bells or the round: Turn Again, Whittington), as the upper line of a two-part contrapuntal framework.

Useful analogies here include the idea of skeletal vertebrae, or a tree without foliage; these denote an essential framework (i.e. structural pitches, normally of consonant harmony) which is completed through the addition of flesh or leaves (i.e. decorative, non-structural pitches). For young beginner students, stepping stones or staircases offer an attractive analogy for structural pitches which can be replicated on the floor of the classroom; children can enjoy moving between stepping stones - so simulating the idea of voice-leading - in response to a teacher's aural signals of short melodic patterns. Of wider applicability, the idea of journeys by various modes of transport usefully demonstrates a 'goal-directed' route consisting of essential pitches (main station stops) and inessential ones (stations passed through without stopping). Equally, the use of well-known popular melodies, as models for particular structural types (see Fig. 10), can offer a tangible source of reference, as well as increasing the accessibility of what might initially seem a somewhat dry discipline, even to the relatively advanced string-player/musician.

The 'Rhythmic and bowing variants' of Figure 1 are used to develop the voiceleading principles established through a series of practical exercises (Figs. 28). The notation and practice of the rhythms - through playing, clapping and reciting employs traditional French time-names and operates on a principle of increasing complexity ('diminution'). These simple opening patterns are helpful as part of a 'warm-up' routine, combined with scales and studies, and, since rhythmic precision and versatility of bowing are not always listed amongst a student's greatest strengths, it can be very useful to embrace a more systematic approach. Furthermore, it can actually be refreshing for students and their teachers to return to French time-names provided that they are employed in a stimulating way: for instance by the creation of imaginative rhythmic counterpoint in small-group tuition. There is no doubt that this approach can significantly enhance the ability to sight-read. 
Voice-leading analysis in string pedagogy and performance Deborah Mawer

(A) Simple metre: $2 / 4,3 / 4$ and $4 / 4$

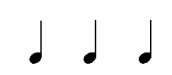

(a) Crotchets, maintaining pulse, e.g. 3/4: 'Taa taa taa' (etc.) Accompanying words for younger students (from Nelson):

'La- zi- ly, Ea-si-ly'

[Vary bowings, e.g. detached; slurred per bar; down bow: two beats, up-bow, one beat; reiterated down-bows; reversed bowings: up/down; varied use of heel, middle and point]

\section{\&?}

(b) Crotchet/rest combinations, e.g. 3/4: 'Taa sh sh'

[Bowing suggestion: reiterated down-bows at heel for crotchets, plus circling motion through crotchet rests]

(c) Full-bar durationsof notes/rests, e.g. 4/4: 'Taa-aa sh-sh' [Bowing: up-bow at point for minim, plus circling motion through minim rest]

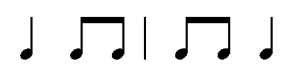

(d) Crotchet/quaver combinations, e.g. 2/4: 'Taa ta-te | Ta-te taa' Words for younger students: 'Beef-burger! Fish and chips!'

[Bowings: up-bow start, bowed-out; up-bow start, slurred quavers; down-bow start, initial re-take]

With syncopations, e.g. 2/4: 'Te-taa-te | Te-taa-te'

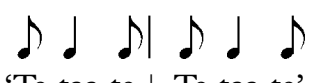

[Bowing: up-bow start for each bar]

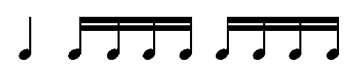

(e) With semiquavers, e.g. 3/4: 'Taa ta-fi-ti-fi ta-fi-ti-fi'

[Bowing: bowed-out, heel to point]

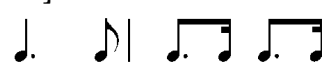

(f) With dotted patterns, e.g. 2/4: 'Taa-a te | Taa-fi taa-fi'

[Bowing: dotted quaver/semiquaver figures slurred in bar 2]

(B) Pattern combinations/extensions including demisemiquavers, triplets, reversed dotted rhythms (short-long), and unusual groupings, e.g.

$3+3+2 / 8$

(C) Compound metres $(6 / 4,6 / 8,6 / 16)$, more complex rhythmic patterns including duplets, quintuplets etc.

(D) Irregular metres $(5 / 4,7 / 4,5 / 8,7 / 8)$, alternating metres, additive rhythms

(E) Patterns adapted from other string repertory

(F) Student-devised patterns

Fig. 1. Rhythmic and bowing variants.

\section{MBRIDGE JUUNALS}


Voice-leading analysis in string pedagogy and performance Deborah Mawer

Beyond the different rhythmic and bowing patterns, teachers and students should vary the format of the exercises as much as possible. The material should be discussed and demonstrated, sung to sol-fa with hand-signs, where appropriate, and then each part played in turn; the exercise can then be performed as a duo or, where feasible, as double-stopping, with various bowing styles (spiccato, sautillé, martelé), tempi, dynamics, tone-colour, character and so on. There need to be clear strategies on the use of durational notation. With beginners, the maintenance of strict rhythmic, rather than structural, notation is desirable to avoid confusion; with more advanced players, it is practicable to offer structural analytical notation, aligned with at least one literal rhythmic realisation.

Structural notation operates at background (most fundamental), middleground and foreground (most decorative) levels. Generally, open-headed notes indicate the interpretation of those pitches as structurally essential; those that are also beamed (joined together) are of the most significant 'fundamental structure'. Filled-in notes with stems denote pitches which are, relatively speaking, decorative or inessential, while those which are filled-in and lack stems represent ornamental diminutions of minimal structural importance, though often providing vital musical interest at surface level. Slurs indicate structural connections between pitches, while slurs denote registral transfer, or the middleground 'prolongation' (structural continuation and reinforcement) of a pitch that underlies more superficial embellishments.

\section{Menu of exercises}

The voice-leading exercises in Figures 2-8 (extracted from the drafted learning package) suggest initial material for violin, designed to establish the basics of a simple 3-2-1 melodic descent, introducing repeated (decorative) pitches and use of upper register and temporal extensions. Each exercise is presented in structural notation, aligned against one possible rhythmic performance realisation; the exercises given as Figures 2-5 support the first stage of this learning approach. Figure 2 projects a 3-2-1 fundamental structure (background level: Bgd.), utilising the lower octave in $\mathrm{D}$ major, with the upper line on the $\mathrm{D}$ string $(m, r, d)$ and the bass line on $\mathrm{G}$ and $\mathrm{D}$ strings $(d, s, d)$. These founding pitches of the two lines are presented as open-headed, beamed notes. The resulting two-part counterpoint (consonant intervals: major third; perfect fifth; perfect unison) may be realised through doublestopping; a first rhythmic realisation might just involve counting four pulses for each pitch.

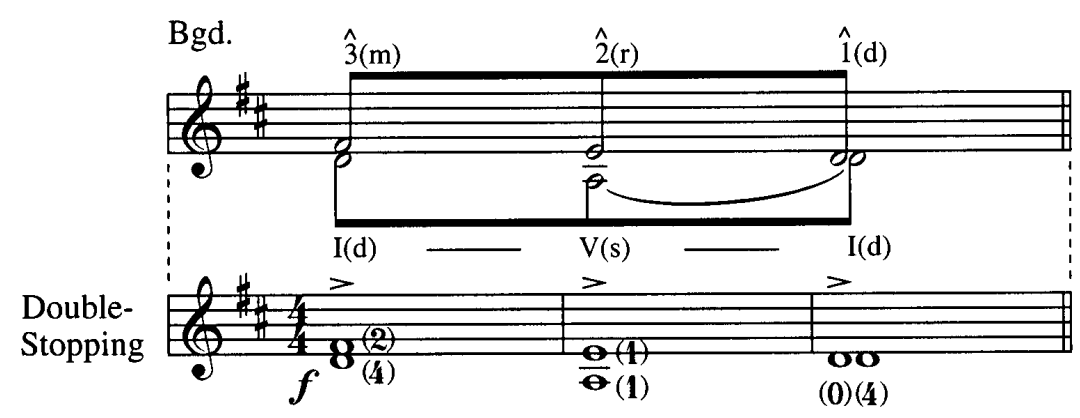

Fig. 2. $\hat{3}-\hat{2}-\hat{1}$ Melodic descent ('Three Blind Mice’ shape!). 
Voice-leading analysis in string pedagogy and performance Deborah Mawer

Figure 3 presents simple repetition as one means of developing the framework, with a measure of detail that encompasses the lower middleground (Lwr. mgd.)/background levels. This is similar to Figure 2, but might involve playing two, four, then eight of each pitch before moving to more complex rhythmic repetitions, punctuated by rests. Students should incorporate ideas from Figure 1, as well as devising their own patterns, and, where appropriate, each short piece produced should be sung as well as played!

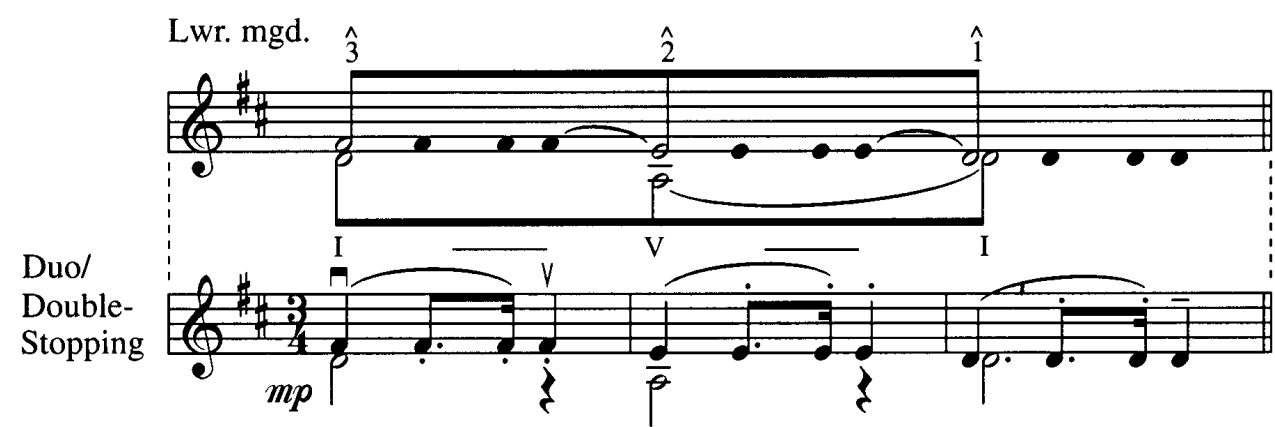

Fig. 3. $\hat{3}-\hat{2}-\hat{1}$ with repeated (decorative) pitches.

Figure 4 shows an upper registral descent (background level). Two interpretations are offered with possible rhythmic realisations: firstly, using A and E strings in first position; secondly, presenting the descent in third position on the A string. Significantly, this demonstrates, admittedly at a basic level, how structure may relate to, and indeed inform, fingering. The use of third position produces a 3, 2, 1 fingering which matches the 3-2-1 descent and provides it with consistency of tone, not offered by the first-position fingering, and of hand position, not achievable by a fingering which interrupted the line with a poor shift. The lower part (I-V-I) may be articulated by open strings or played entirely on the $\mathrm{D}$ string, in first or third positions.

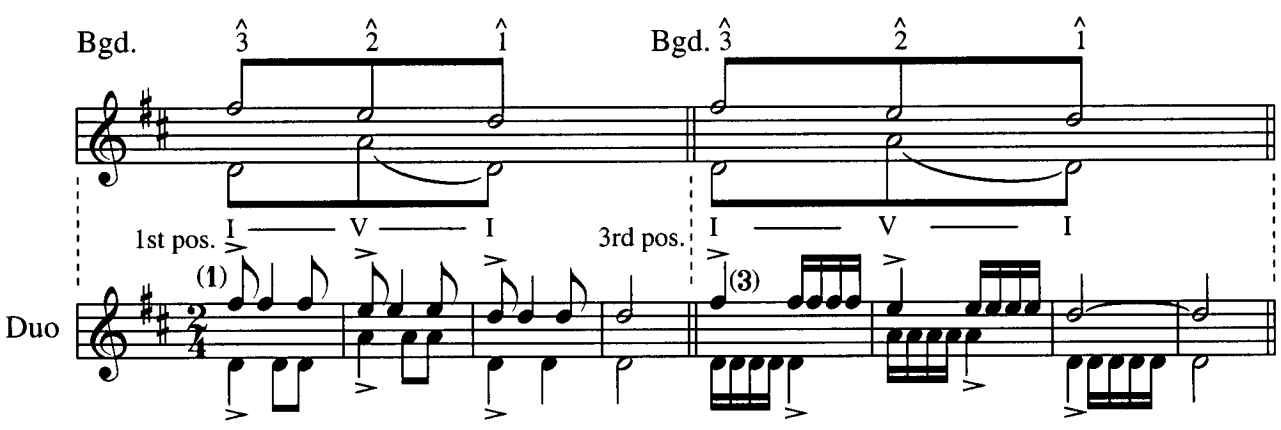

Fig. 4. $\hat{3}-\hat{2}-\hat{1}$. New (upper) register.

This principle can be developed in more complex contexts where consistency of tone (and hand position) is desirable in replicating sequences and in connecting slurred pitches, as in much unaccompanied Bach (a point demonstrated later in Fig. 9). Figure 5 (Allegretto ritmico) is to be worked as Figure 2, but with the structural 3 sustained by some means for a longer period (opening/middle of piece), followed by $2-1$, as the ending (i.e. perfect cadence).

The exercises in Figures 6-8 continue explorations of register and repetition, 
Voice-leading analysis in string pedagogy and performance Deborah Mawer

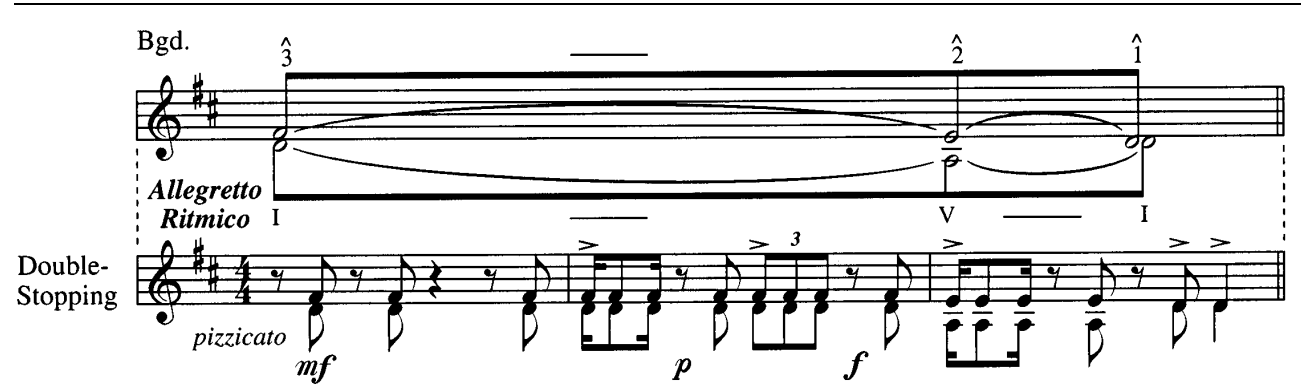

Fig. 5. $\hat{3}-\hat{2}-\hat{1}$. Structural $\hat{3}$ extended in time.

together with new means of producing decorative diminution, through neighbour notes (upper: $\mathrm{UN}$ and lower: $\mathrm{LN}$ ), passing notes (PN), third and fifth progressions (3rd-prg.; 5th-prg.), chordal notes (CN), and combined techniques. Figure 6 combines registral transfer (reg. tr.) and repetition, now also including the lower voice, and provides one of many performance interpretations as an Andante maestoso in $5 / 4$ metre.

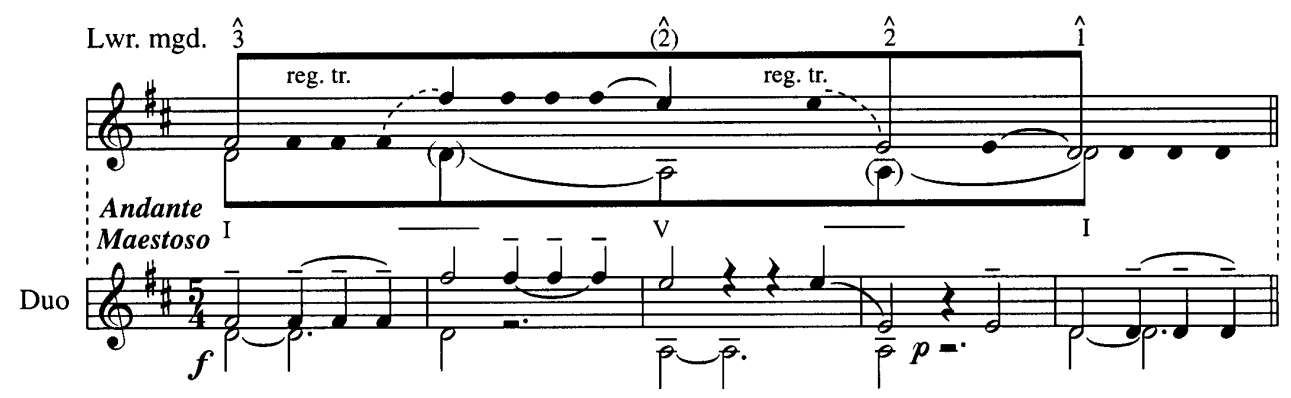

Fig. 6. $\hat{3}-\hat{2}-\hat{1}$. Different registers and repetition.

Figure 7 (Allegro barbaro: middleground/background levels) incorporates upper and lower neighbour notes in both voices, indicating the prolongation of structural pitches beneath the more superficial embellishments by means of broken slurs. The principle of increasing complexity is continued in further exercises (not quoted here) which span the progression between Figures 7 and 8.

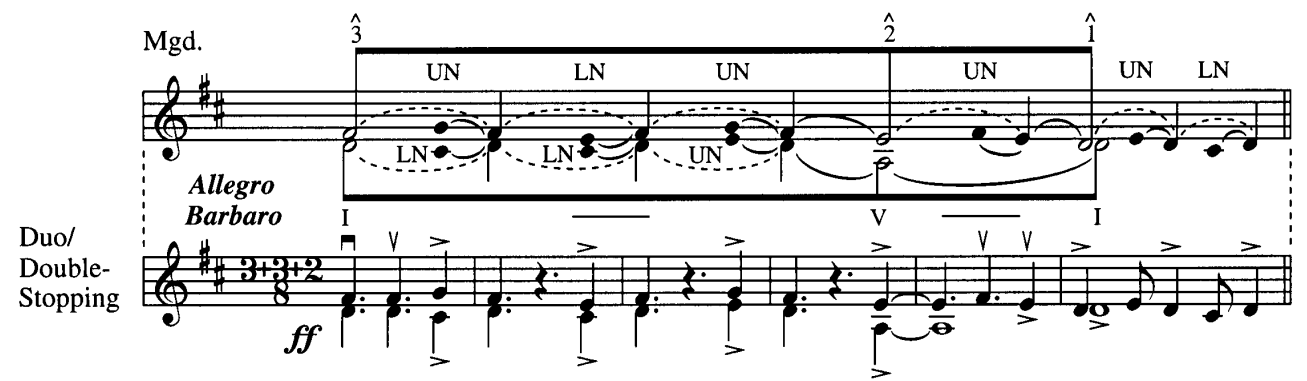

Fig. 7. $\hat{3}-\hat{2}-\hat{1}$ with neighbour (auxiliary) notes (UN/LN).

The final exercise, quoted as Figure 8 (operating from foreground through to background level: Urlinietafel), shows how ideas can develop, with more complex and varied diminution, including double neighbour notes $(\mathrm{DN})$. One performance realisation is given in the shape of a Pastorale, though there could be many other interpreta- 
Voice-leading analysis in string pedagogy and performance Deborah Mawer

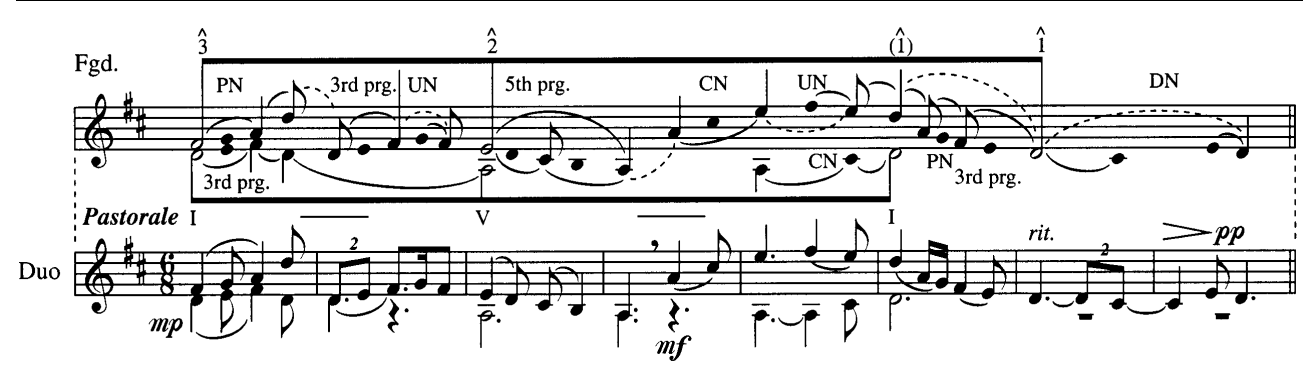

Fig. 8. $\hat{3}-\hat{2}-\hat{1}$ with more complicated decorations.

tions of metre, rhythm, dynamics and character. A good case can be made for choosing bowing patterns which correlate with the structural slurs denoting third and fifth progressions and chordal arpeggiation, as in the given realisation.

Interestingly, detailed voice-leading studies of Bach's music for unaccompanied strings suggest a surprisingly strong correlation between his articulation/bowing marks and voice-leading analytical slurs denoting harmonic and melodic connections. Figure 9 adopts this comparative stance in a structural interpretation of the 'Menuetto' from Bach's Cello Suite No. 1, transcribed for viola. The upper staff of the graph shows the transcribed music with its articulation markings (source: Neue Bach-Ausgabe [VI/2], 1988: 58) and possible fingering patterns. The aligned lower staff offers a structural reading along Schenkerian lines. The extent of correlation between surface and structural markings further suggests the naturalness of coupling voice-leading analysis and performance.

\section{Variations and extensions}

In addition to the variants described above, the student might make other modifications and refinements by playing the exercises in equivalent minor keys (i.e. maw, ray, doh; 'Three sad mice'!), as well as transposing them into other keys, firstly perhaps G and A majors, in first and third positions, followed by more remote transpositions and higher position-work.

Beyond traditional tonality, there is a good argument for freeing up the methodology in order to investigate characteristics of the wide range of diatonic and other modes (e.g. lydian, mixolydian, phrygian modes; pentatonic, whole-tone collections; blues scales). In any context, the relationship between structural patterns and those of fingering and bowing should be fully explored. In some instances, it will be desirable to match bowing and fingering to structural connections denoted by slurs; at other times, it may actually be effective to contradict the structural slurs by changing the bow, string, or left-hand position.

Other possibilities include looking at ways of extending structures, one of which could involve formal interruption (a divided descent): 3-2//3-2-1 (see again Fig. 9). Additionally, before reaching the first structural pitch, the player might introduce a partial or full arpeggio from a note of the tonic chord (opening arpeggiation). For a 3-2-1 structure in $\mathrm{D}$ major, she/he might just play the $\mathrm{D}$ (tonic) before the $\mathrm{F} \#$ (3), although, if the descent was to be presented in the upper octave, she/he might introduce the full arpeggio, $\mathrm{D}-\mathrm{F} \sharp-\mathrm{A}-\mathrm{D}$, before the $\mathrm{F} \sharp(3)$.

Finally, Figure 10 offers examples from an anthology of violin melodies, many of which appear in an elementary method, Abracadabra Violin (Davey, 1997), while others are cited from folk-fiddle collections. These melodies are utilised at beginner 
Voice-leading analysis in string pedagogy and performance Deborah Mawer

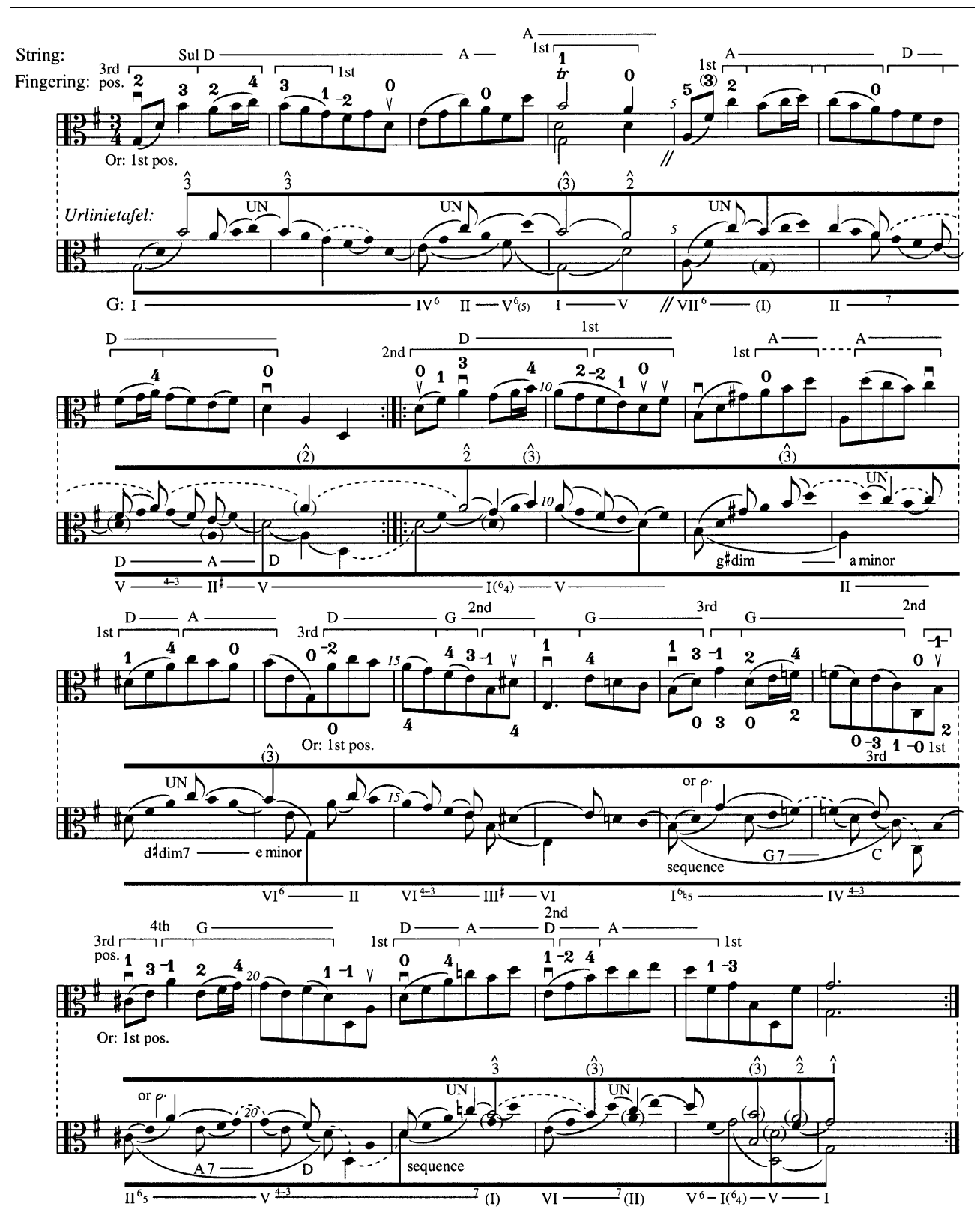

Fig. 9. J. S. Bach, Menuetto I, Cello Suite No. 1 in G. major (for viola). Correlation between Bach's articulation/bowing marks and structural connections (also informing choice of fingering).

level, but are included here too partly as models to illustrate voice-leading descents from $3(m), 5(s)$, and $8(d)$, in conjunction with a simple second part, within more light-hearted repertory. They also serve to show that the main analytical principles can be extended to more modal contexts. Flexibility remains an important issue: sometimes it is feasible to interpret a piece in terms of two different descents occurring at different points, while another melody may resist this treatment altogether, perhaps involving simply an arpeggio outline, or even an ascending fundamental line. 
Voice-leading analysis in string pedagogy and performance Deborah Mawer

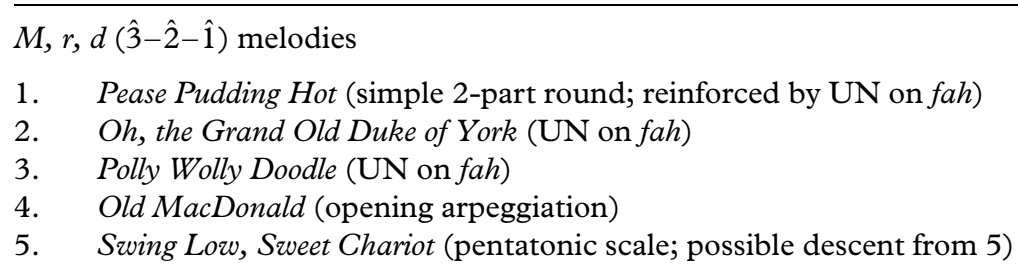

$S, f, m, r, d(\hat{5}-\hat{4}-\hat{3}-\hat{2}-\hat{1})$ melodies

1. Christmas is Coming, the Geese are Getting Fat (4-part round, UN on lah)

2. Christmas is Coming and Then the New Year (3-part round)

3. My Paddle's Clean and Bright (modal, gapped scale, 4-part round)

4. We're All Going on a Summer Holiday

5. Frère facques (opening arpegg.)

6. Good King Wenceslas

7. Twinkle, Twinkle Little Star; or Baa-Baa Black Sheep (UN on lah)

8. Bobby Shaftoe (opening arpegg., interrupted descent; possible descent from 3)

$D, t, l, s, f, m, r, d(\hat{8}-\hat{7}-\hat{6}-\hat{5}-\hat{4}-\hat{3}-\hat{2}-\hat{1})$ melodies

1. Tink-a-tink (Scot's fiddle tune, opening arpegg.)

2. Kookaburra (opening arpeggiation, 4-part round)

3. Irish Washerwoman (opening arpegg.; descent through second half)

4. Shalom (modal/hexatonic)

5. Land of the Silver Birch (modal/pentatonic)

6. Turn Again, Whittington

Fig. 10. Selected melodic models.

At this point, it would be appropriate for string-players to create their own improvised pieces on a 3-2-1 framework, ensuring that they have a sense of opening, middle and close. It may be helpful to begin by considering a certain mood, visual image or dance style. Students could experiment firstly with repetitions, using pitches in different octaves, and then with neighbour notes (a step higher or lower than the main pitches). Passing notes, scalic fragments, and additional chordal notes could be introduced, while developing rhythmic patterns in accordance with the chosen style. Pieces should then be rehearsed and performed, ensuring that structural frameworks are maintained beneath the decorations. Having progressed through a menu of these exercises, in combination with repertory of the student's choice, the tertiary-level string-player would then be able to engage with the selected advanced case studies (such as the sample given in Fig. 9).

\section{Implementation of 'Voice-leading for Strings'}

\section{Informal pilot scheme (1994-7)}

'Voice-leading for Strings' has been tested informally in trials at the University of Newcastle-upon-Tyne (1994-5) and Lancaster University (1995-7). 0 In the Newcastle experiment, this material was embedded as the first of four research studies within a ten-week third-year music course on 'Performance and analysis'. The aim, objectives and materials of the project were discussed across a period of about three weeks. A group of eight students on this course came from a range of backgrounds:

\section{0}


some had extensive analytical training; others, while proficient practitioners (mainly violinists and pianists), had no prior knowledge of voice-leading analysis.

In the Lancaster experiments, the project was embedded within a five-week thirdyear music course (1995-6: group A of fifteen students; 1996-7: group B of eight students) entitled 'Musical structure and interpretation: Issues for analysis and performance'. All students had some grounding in voice-leading analysis and were also proficient instrumentalists (mainly violinists, flautists, cellists and pianists).

At both locations, there was at least one mature student with considerable experience of instrumental teaching. In all three experiments, attention was divided between the practice and discussion of the introductory exercises for advanced level and the case studies. Additionally, students studied a small collection of further texts (Berry, 1989; Edlund, 1994; Lester, 1995; Dunsby, 1995).

In the introductory exercises, students produced their own short pieces based around particular descents and characterisations (played 'by ear'). They also experimented with Kodály hand-signs while extemporising on the basic descents. Two students, creating a two-part framework, would provide aural signals for the rest of the group to respond to; occasionally, one adept student would endeavour to achieve similar effects with two hands working independently!

For the assessed case studies at Lancaster University, three subgroups of students were each assigned a Sarabande from one of the Bach suites: Partita No. 1 in B minor for Violin (and, with modifications, other treble-clef melody instruments, especially flute); Cello Suite No. 2 in D minor (with modifications for other bass-clef melody instruments); French Suite No. 1 in D minor for keyboard players. In each context, students considered the relationship between issues of performance interpretation and musical structure. For instance, experimenting with different interpretations of analytical structural slurs in relation to questions of phrasing and bowing. They also weighed up the merits and shortcomings of various editions of the score and performances of the work. Additionally, for Bach's Partita No. 1, students produced their own diminutions as equivalents of Bach's double variations (both 'by ear' and fully notated).

Each of the student subgroups presented their findings collectively in a seminar format at the end of the five-week unit, using performance illustrations (including comparisons of 'before' and 'after' the course tuition), collaborative written papers and informal discussion. All students then wrote up their individual responses to be assessed formally by the course tutor.

\section{Findings}

The informal findings were measured by verbal discussion (Newcastle and Lancaster), questionnaire and case-study assessments (Lancaster). From an analytical stance, almost all students felt that this was a much more engaging way to teach analysis; that it made a greater impact when related to their own instrument; and that their ideas had developed significantly across the course. The incorporation of Kodály handsigns in the exercises was particularly enjoyed. It was acknowledged, however, that analytical theory might not always marry as naturally or closely with performance as in the chosen examples.

From a performance stance, there was greater variety of response. As regards the exercises, several of which were adapted for instruments other than strings, some students found the practice of improvisation around a framework quite instinctive; others found the approach challenging since they seemed to have mislaid their powers 
of imagination within an instrumental curriculum that had tended to focus exclusively on the notes of a score (a view supported by Priest, 1989: 173), perpetuating the idea that, essentially, there was only one way of doing things. Fundamentally, these students regarded themselves as passive replicators, rather than active instigators. After initial anxiety and lack of inspiration, however, they started to overcome their inhibitions and to enjoy the new-found freedom.

Questionnaires and assessment profiles for the Lancaster groups A and B produced additional data, tabulated in summary form as Figure 11, which provided a strong overall endorsement of the synthesised course design and suggested symbiotic relationship. The group A (1995-6) data was based on 12/15 questionnaire returns and that for group B (1996-7) on 8/8 returns. The first batch of questionnaires was used to inform the second year of the trial by way of small-scale refinements, and so may constitute one reason for the generally rather higher percentages received in 1996-7. Further to the tabulated statistics, 25 per cent of student-group A felt that they had slightly too much course material to take on board, while group B was notably more confident of keeping up with the work-load (as suggested by responses to statements 5. and 6. in Fig. 11a).

Asked which aspects of the synthesised course curriculum were 'particularly easy', the group A respondents highlighted the 'practical/intuitive aspects' and also remarked that 'the topic was easy to follow'. 'Particularly difficult' areas included for some the concepts, and for others the musical application. Additional comments were that some students found the discussion subgroups (consisting of five students) rather large, believing that this made it 'difficult to condense all our ideas'; others concluded that it was 'interesting to question ideas of structure and interpretation'.

When the group B respondents were asked what was 'particularly easy', they highlighted informal discussion; about half subscribed to the view that 'It was a challenging course, therefore no easy part, but very interesting'. Some identified the 'theory and practice [of analysis] in performance' as easy, while for others it was 'Relating aspects of performance to analysis, i.e. showing how there is a reciprocal relationship' which proved 'particularly difficult', together with an acknowledgement that, to some extent, the 'Subject-matter is open-ended'. Students' additional comments focused on their enjoyment of the course, not least because the approach within this experimental teaching project was appreciably different and novel in relation to other areas of their curriculum. A suggestion that the course should be extended usefully supported the notion of a longer-term pilot scheme: 'Found it a very interesting course - it would be good if it was a ten-week course with more time to explore the ideas of structural and interpretative signs'.

'Final tutor assessments' for groups A and B are illustrated in Figure 11b and show a marked increase in student achievement across the two years of the study. This may be attributed to several factors: the second student group was of more closely matched ability and smaller in number; course delivery and content had been modified slightly in the light of previous experience.

\section{Proposed formal pilot scheme}

The formal implementation of 'Voice-leading for Strings' follows practices endorsed by Cohen and Manion (1992: 196-8; 208-9), with the intended pilot scheme at Lancaster University, and perhaps also in surrounding schools and private settings, subscribing to the notion of 'true experimental' work (Campbell \& Stanley, 1963), together with a concern for good design (Kerlinger, 1970). The chosen model is 
Voice-leading analysis in string pedagogy and performance Deborah Mawer

\begin{tabular}{|c|c|c|}
\hline \multirow[b]{2}{*}{ Summary of coverage/findings of questionnaire: } & \multicolumn{2}{|c|}{$\begin{array}{l}\text { Student responses in } \\
\text { support of statements } 1-6 \text { : }\end{array}$} \\
\hline & $\begin{array}{l}\text { Group A } \\
(1995-96)\end{array}$ & $\begin{array}{l}\text { Group B } \\
(1996-97)\end{array}$ \\
\hline 1. Teaching approach increased interest in subject-matter & $75 \%$ & $100 \%$ \\
\hline 2. Synthesised course was well/very well structured & $75 \%$ & $88 \%$ \\
\hline 3. Course was well/very well presented & $75 \%$ & $100 \%$ \\
\hline 4. Learning package handouts were useful/very useful & $83 \%$ & $75 \%$ \\
\hline 5. Quantity of course materials was appropriate & $67 \%$ & $75 \%$ \\
\hline 6. 10+ hours needed to complete case-study assignment & $92 \%$ & $63 \%$ \\
\hline
\end{tabular}

Fig. 11a. Student questionnaire responses for 1995-97.

\begin{tabular}{lllll}
\hline & \multicolumn{2}{l}{ Final tutor assessments: } & \\
& $\begin{array}{l}\text { Excellent } \\
\text { (I) }\end{array}$ & $\begin{array}{l}\text { Good } \\
\text { (IIi) }\end{array}$ & $\begin{array}{l}\text { Fair } \\
\text { (IIii) }\end{array}$ & $\begin{array}{l}\text { Satisfactory } \\
\text { (III) }\end{array}$ \\
\hline $\begin{array}{l}\text { Group A } \\
(1995-96)\end{array}$ & $7 \%$ & $43 \%$ & $36 \%$ & $14 \%$ \\
$\begin{array}{l}\text { Group B } \\
(1996-97)\end{array}$ & $25 \%$ & $50 \%$ & $25 \%$ & - \\
\hline
\end{tabular}

Fig. 11b. Final tutor assessments for 1995-97.

'commonly used in educational experimentation' (Cohen \& Manion, 1992: 196) and consists of experimental and control groups, ideally of randomised make-up (or, if insufficient numbers, at least of roughly equivalent make-up in relation to history, maturation, etc.), in order to help control extraneous variables. Campbell and Stanley strongly support 'this simple and elegant experimental design' to the extent that 'threats to internal validity are ... controlled in the pre-test post-test control group design' (Cohen \& Manion, 1992: 198). Since pre-testing may bias results, the model acknowledges the refinements of Harvey and Cooper (1978), the origins of which lie in the influential early work of Solomon (1949). Thus, the project will use a second control group which is not pre-tested but which does receive the tuition and posttesting.

The best subjects for the experiment at advanced level are likely to be first-year students who have a basic awareness of formal analysis, but not yet any voice-leading experience. The experimental model can be expressed in tabular fashion, and the design of the project is likely to span one academic year (as shown in Fig. 12). Term 1 will comprise initial consultation between students and teachers and pre-testing of small student groups (including controls) by performance (taped or live) and questionnaire. The 'test' will then proceed with introductory exercises at advanced level (together with the equivalent material at beginner and intermediate levels). Terms 2 and 3 will concentrate on selected case studies (at advanced and other levels). At the end of term 3, post-testing will comprise performance (taped or live), questionnaire and evaluative discussion with students and teachers, including comparative study with the control groups. 
Voice-leading analysis in string pedagogy and performance Deborah Mawer

\begin{tabular}{llll}
\hline & Temporal sequence: & & \\
Student groups: & $\begin{array}{l}\text { Pre-test } \\
\text { (Term 1) }\end{array}$ & $\begin{array}{l}\text { Test } \\
\text { (Terms 1, 2, 3) }\end{array}$ & $\begin{array}{l}\text { Post-test } \\
\text { (Term 3) }\end{array}$ \\
\hline Experimental group (A) & Assessment (1) & Test curriculum & Assess. (2) \\
\hline 1st Control group (B) & $\begin{array}{l}\text { Assessment (3) } \\
\text { 2nd Control group (C) }\end{array}$ & $\begin{array}{l}\text { [No curriculum] } \\
\text { Test curriculum }\end{array}$ & $\begin{array}{l}\text { Assess. (4) } \\
\text { Assess. (5) }\end{array}$ \\
\hline
\end{tabular}

Fig. 12. Model for operation of formal pilot scheme.

\section{Conclusion}

This article has sought to demonstrate how analysis - especially the voice-leading variety - and string pedagogy may serve each other in a symbiotic relationship which can then be realised in performance (in turn stimulating further new ideas). The notion will not, however, be without its critics: there are those who believe that the days of Schenker et al. are numbered, if not over, and that such an approach is too restrictive, even risky, to be beneficial (Howell, 1996: 126-7). My response is that there is still purpose in a classic, yet imaginative, introduction to voice-leading analysis within the central tonal repertory; that it is helpful, at least initially, to delineate boundaries; and that students (and indeed instrumental teachers) will, in time, be in a stronger position to question restrictions and make decisions for themselves. If there is no methodological characterisation, analytical thinking may be undersold, undervalued, and diluted in its usefulness.

These issues genuinely need more debate, both in the UK and overseas. Initial discussion might be channelled through the networks of the European String Teachers' Association (ESTA), the Associated Board of the Royal Schools of Music (ABRSM), and the Society for Music Analysis (SMA), as well as through various institutions of higher education; the original proposal has already been favourably received by the ISME. Clearly, these ideas need now to be subjected to the rigours of a full pilot scheme, and will doubtless be modified in the process. Ultimately, the case for 'Voice-leading for Strings' must be proved or disproved through the practice of performance and through the broader experience of students and teachers, and so it is appropriate to end by thanking those who willingly involved themselves in the initial testing of these materials.

\section{References}

Aldwell, E. \& Schachter, C. (1989) Harmony and Voice-leading. New York, London: Harcourt Brace Jovanovich.

Bach, J. S. (1988) Sechs Suiten für Violoncello Solo. H. Eppstein (Ed). In Neue Bach-Ausgabe. VI/2, p. 58. Kassel: Bärenreiter.

Berry, W. (1989) Musical Structure and Performance. New Haven: Yale University Press.

Bruhn, S. (1990) 'Reconsidering the Teacher-Student Relationship in the Training of the Performing Musician', International fournal of Music Education, 15, pp. 13-22.

Bruhn, S. (1993) F. S. Bach's Well-Tempered Clavier: In-depth Analysis and Interpretation. Hong Kong: Mainer International.

Campbell, D. T. \& Stanley, J. C. (1963) 'Experimental and Quasi-Experimental Designs for 
Voice-leading analysis in string pedagogy and performance Deborah Mawer

Research in Teaching', in N. L. Gage (Ed), Handbook of Research on Teaching. Chicago: Rand McNally.

Choksy, L. (1988) Kodály Method, Comprehensive Music Education from Infant to Adult. Englewood Cliffs, NJ: Prentice Hall.

Cohen, L. \& Manion, L. (1992) Research Methods in Education. London, New York: Routledge.

Cone, E. T. (1968) Musical Form and Musical Performance. New York: Norton.

Cook, N. J. (1987) A Guide to Musical Analysis. Oxford University Press.

Davey, P. (1997) Abracadabra Violin. London: A. \& C. Black.

Dunsby, J. \& Whittall, A. (1988) Music Analysis in Theory and Practice. London: Faber.

Dunsby, J. (1995) 'Design in Music', in Performing Music: Shared Concerns, pp. 79-95. Oxford: Clarendon Press.

Eales, A. (1992) 'The Fundamentals of Violin Playing and Teaching', in R. Stowell (Ed), The Cambridge Companion to the Violin, pp. 92-118. Cambridge University Press.

EdLund, B. (1994) 'Musical Interpretation and the Ontology of the Music Work', in H. Lees (Ed), Musical Connections: Tradition and Change. Proceedings of the 21st World Conference of the International Society for Music Education, pp. 245-51. Tampa, FL: ISME.

Forte, A. \& Gilbert, S. (1982) Introduction to Schenkerian Analysis. New York, London: Norton.

Gellrich, G. \& Parncutt, R. (1998) 'Piano Technique and Fingering in the Eighteenth and Nineteenth Centuries: Bringing a Forgotten Method Back to Life', British fournal of Music Education, 15/1, pp. 5-23.

Harvey, T. J. \& Cooper, C. J. (1978) 'An Investigation into Some Possible Factors Affecting Children's Understanding of the Concept of an Electric Current in the Age Range 8-11 Years Old', Educational Studies, 4/2, pp. 149-55.

Howell, T. (1996) 'Musical Analysis: Back to Basics', British fournal of Music Education, 13/2, pp. $123-34$.

Kerlinger, F. N. (1970) Foundations of Behavioral Research. New York: Holt, Rhinehart \& Winston.

Lester, J. (1995) 'Performance and Analysis: Interaction and Interpretation', in J. Rink (Ed), The Practice of Performance, pp. 197-216. Cambridge University Press.

Mawer, D. (1992) “"Composing out”: The Principles of Music Analysis across the Wider Musical Community', Society for Music Analysis Nerwsletter, 1, pp. 8-12.

MAwer, D. (1997) 'Embedding CD-tours in HE Courses: Experience with the Analytical Listening Guide to Darius Milhaud: La Création du monde', Musicus: Computer Applications in Music Education, 5, pp. 19-29.

Nelson, S. M. (1985) 'The Tower Hamlets Project: A Personal Review', British fournal of Music Education, 2/1, pp. 16-93.

PrIEst, P. (1989) 'Playing by Ear: Its Nature and Application to Instrumental Teaching', British Fournal of Music Education, 6/2, pp. 173-91.

RaInbow, B. (1990) 'The Kodály Concept and its Pedigree', British Fournal of Music Education, 7/3, pp. 197-204.

Rink, J. (1995) The Practice of Performance. Cambridge University Press.

Rolland, P. (1974) The Teaching of Action in String Playing. Urbana, IL: Illinois String Research Associates.

SAlzer, F. (1982 [1952]) Structural Hearing. London: Dover.

Schenker, H. (1979 [1935]) Free Composition (trans. E. Oster). New York: Longman.

Solomon, R. L. (1949) 'An Extension of Control Group Design', Psychological Bulletin, 46, pp. $137-50$.

Verney, J. (1991) 'The Integrated Instrumental Teacher: Learning to Play through Performance, Listening and Composition, British fournal of Music Education, 8/3, pp. 245-69.

Wright, R. (1998) 'A Holistic Approach to Music Education', British fournal of Music Education, 15/1, pp. 71-81. 